\title{
Impact of Healthcare Marketing and Branding on Hospital Services
}

\author{
${ }^{1} \mathrm{P}$ Naveen Kumar, ${ }^{2}$ Anil Jacob, ${ }^{3}$ Smruthi Thota
}

\begin{abstract}
Healthcare is one of the many human-centered services offered, the other being legal services, hospitality services, transport services, etc. The healthcare is also the foremost in all of these personal services. Every section of the healthcare experience must embody and convey the message that the hospital is the center of health and wellness in the community. The connection between healthcare provider and patient needs to be developed to improve the delivery model.

However with the rise of healthcare costs to providers, increase in operating costs, informative and knowledgeable customers; hospitals need branding to drive strategies, convey their expanding range of services, make an emotional connection with customers and create lasting relationships thereby generating profits.

Companies are losing out because there is often little or no integration between Corporate Social Responsibility (CSR) and marketing departments and their respective strategies. This misses brand building opportunities and may also confuse as well as disenfranchise company stakeholders.

Unless CSR becomes central to the marketing director's agenda, it will not have the desired effect and can potentially create a backlash. The nature of the business - category, customers, competitors - should dictate how much and in which ways, a company should promote its CSR-related activities.

Here, it lies the importance of developing a more strategic, distinct, sustainable and well defined brand platform. It is ultimately the hospital's brand and the customers' ability to trust that will aid in the decision-making process between competitive healthcare hospitals. Patient expectations and desires are changing, altering the competitive landscape. Employees are a hospital's most vital force and communication medium. Thus, the brand is the greatest asset for uniting employees around a singular culture and mission. This study highlights a conceptual framework that can be used for healthcare organizations to develop the revenues based on branding.
\end{abstract}

Keywords: Healthcare branding, Brand image, Corporate social responsibility, Integrated marketing communication, Customer satisfaction index.

${ }^{1}$ Assistant Professor, ${ }^{2}$ Senior Manager, ${ }^{3}$ Management Trainee

${ }^{1}$ Department of Hospital Administration, Kasturba Medical College and Hospital, Manipal, Karnataka, India

${ }^{2}$ Kasturba Hospital, Manipal, Karnataka, India

${ }^{3}$ Department of Public Health, Manipal University, Manipal Karnataka, India

Corresponding Author: P Naveen Kumar, Assistant Professor, Department of Hospital Administration, Kasturba Medical College and Hospital, Manipal-576104, Karnataka India, e-mail: naveenpdr@yahoo.co.in
How to cite this article: Kumar PN, Jacob A, Thota S. Impact of Healthcare Marketing and Branding on Hospital Services. Int J Res Foundation Hosp Healthc Adm 2014;2(1):19-24.

Source of support: Nil

Conflict of interest: None

\section{INTRODUCTION}

Hospitals, nursing homes, hospices, physician practices, managed care organizations, rehabilitation centers and other health care organizations did not think about marketing until the early 1970s. In the early years, healthcare professionals did not like the amalgamation of the words healthcare and marketing. Many misconstrued marketing for advertising, and advertising for healthcare services was considered inappropriate. Therefore, healthcare service providers had long resisted the incorporation of formal marketing activities into their operations.

Now however, the environment is changing with focus shifting from an organization being product or service oriented to being user-oriented. The marketer aims to serve the customers in order to improve customer relationships and indirectly increase revenues of the organization.

\section{BRANDING OF HEALTHCARE}

Every hospital stands for a certain image or brand value either low cost care or specialized services. It is of essential importance that everyone on staff from the CEO to the volunteer at the reception desk should communicate the organization's mission effectively. The result is a brandguided organization.

A favorable hospital brand image stimulates patient loyalty directly and also enhances patient satisfaction through the improvement of service quality, which in turn promotes the revisiting intention of patients. Thus, in the competitive healthcare environment hospitals thus should focus their marketing efforts on effective and strategic brand management. A brand can be defined as, 'the customer's perception of a product, service, experience or organization'. Thus, a brand from a marketing or consumer perspective is the promise and delivery of an experience; from a staff perspective is a culture and mission; and from a business perspective is the security of future earnings. 
A brand is far more than a symbol. A brand is a symbol of self-expression that is used to gain acceptance. They embody tangible and intangible qualities that create value which influences both how an organization functions and how it is perceived, internally by the organizations workforce and externally by the customers.

\section{BRAND IMAGE}

Brand image is a composite of perceived quality and esteem dimensions. It is the perception of a brand that is held in a customer's memory and reflects the customer's overall impression. A positive brand image can be considered as a crucial ability of a corporation to hold on its market position. The brand is a valuable intangible asset, which is difficult to imitate, and which is helpful to achieve sustained performance.

The goal of branding therefore is to create a consistent perception of what a company stands for and what they believe in. There is substantial investment in branding but it has a huge payoff. Strong brands build differential equity. Brands make business easier because a business is known by the brand name that they carry. With so many services being part of the market and the customer being well informed, the commodity needs to be branded to leave an impression on the minds of the consumer. Therefore, it is imperative to always brand the service if the organization wants to be noticed, differentiated and viewed as more than just any other organization offering the same services as others.

In the healthcare context, Kotler and Shalowitz (2008) suggested that hospital brand image is the sum of beliefs, ideas and impressions that a patient holds toward a hospital. A brand image of a hospital is not absolute; it is relative to brand images of competing hospitals. ${ }^{1}$ The patients often form a brand image of a hospital from their own medical examination and treatment experiences (Kim et al, 2008). ${ }^{2}$ The growth of senior citizens population in our country and growing focus on health are dynamically increasing particular health wants and needs within the general populace. The current medical service market favors the buyer rather than the seller (Lee et al, 2010). ${ }^{3}$ Hence, the field of medical service is now emphasizing the importance of customeroriented marketing. Equally, any company undertaking and promoting CSR initiatives needs to be aware of the risks and benefits that accompany such efforts. This requires that CSR and marketing cooperate to develop a sustainable effort that brings competitive advantage. Simply talking about CSR is not enough, it needs to be supported by actual business practices, brand imaging, consistent communications and experienced by customers in very tangible ways.

This study encompases as a whole the importance of developing brand power of this hospital to sustain in today's competitive enviornment. The main goal of a marketer is the ability to create, enhance, maintain and protect brands. However, most product companies are aware of the strategic need to craft and manage brand identity. But, at many healthcare service organizations, branding is not strategic but only tactical and frequently is limited to controlling the use of the corporate identity.

This is where the marketing department of Kasturba Hospital, Manipal, plays an important role in strategic brand management. Brand management involves the design and implementation of marketing activities and programs to build measure and manage brands to maximize their value. The brand management is being performed under following strategies.

\section{STRATEGIC BRAND BUILDING}

The brand should suggest something about the benefits of the service offered. It should suggest the qualities offered by the service. The brand building strategies focused by the organization under this study are as follows:

1. Corporate social responsibility

2. Loyalty programs

3. Integrated marketing communication.

\section{Corporate Social Responsibility (CSR)}

Corporate social responsibility has a number of definitions however in the context of a tertiary care hospital, the one defined by Kristiane and Posner is ${ }^{4}$ 'conducting business in a responsible way that delivers value not only to the organization but also to its stakeholders and the community within which it operates.' Corporate social responsibility is about character and conduct, where integrity and responsibility run right through every seam of the organization's activities and ethos.

\section{Loyalty Programs}

Loyalty building requires the company to emphasize the value of its products or services and to show that it is interested in building a relationship with the customer.

A loyal customer is one who:

- Makes regular purchases

- Purchases across product and service lines

- Refers others

- Demonstrates immunity to the pull of the competition.

\section{Integrated Marketing Communication}

The first definition for integrated marketing communication came from the American Association of Advertising Agencies in 1989, defining IMC (integrated marketing communication) as: 'the approach to achieving the objectives of a 
marketing campaign through a well-coordinated use of different promotional methods that are intended to reinforce each other.' The main advantage with IMC is that it uses the intrinsic strengths of each communication channel in order to achieve a greater impact together. In IMC models, there is often a lack of a specific hierarchy of importance - all components of the model play an equally important role in communicating their brand image.

\section{SERVICE AND CUSTOMER SATISFACTION}

Every organization is formed on the basis of key ingredients. In the field of medical service, Kim et al (2008) $)^{5}$ adopted the concept of customer satisfaction and defined that patient satisfaction is the judgment of perceived value and sustained response toward service related stimulus before, during or after the consumption of medical services by a patient. Patient satisfaction is concerned with the degree to which the expectations of a patient are fulfilled by the medical services. Customer satisfaction may influence brand equity through one direct and one indirect channel. Remarkably, brand equity measures can include customer mindset as well as product market and financial market outputs related to brands (Ailawadi et al, 2003). ${ }^{6}$

Companies consider improved customer satisfaction as being a principal strategy for gaining loyalty, improving willingness to pay and enhancing the lifetime value of the customer to the firm (i.e. customer equity) ${ }^{7,8}$

\section{AIM}

To study the importance of marketing of services by an organization on its brand building and customer satisfaction.

\section{OBJECTIVES}

1. To study the marketing strategies followed and how the marketing strategies help to build the brand of the hospital.

2. To study the buying pattern of health card introduced by the organization.

3. To study the customer satisfaction indices over a 12-month period.

\section{METHODOLOGY}

The study is set in the Marketing Department of Kasturba Hospital. Kasturba Hospital is a 2,032 bedded, specialty and super-specialty medical and surgical care center. Kasturba Hospital (KH), Manipal, is an apex teaching hospital of the Kasturba Medical College (KMC), Manipal, under the aegis of Manipal University. Besides meeting the health demands of the western region comprising Goa, coastal Karnataka and
Kerala, its healthcare network extends to the areas of interior Karnataka, primarily through its satellite hospitals as well as unique healthcare centers. It is recognized for treatment by central and state government, defence services and public sector companies.

The methods used are:

1. Studying the records of the marketing department to make note of: channels of advertising used by the hospital, number of camps conducted by hospital, role of Arogya card in building the brand, role of medical and nursing care in enhancing customer satisfaction during their stay in hospital.

2. A retrospective study was carried out to understand the trends of the patient traffic in hospital and trend in purchase of Arogya card by general public, referrals from camps. This helps in studying importance of marketing of services.

3. A retrospective data analyzed from the customer feedback cell of Kasturba Hospital, Manipal, to study the customer satisfaction index.

\section{RESULTS}

Kasturba Hospital, Manipal, is active in corporate social responsibility. The organization makes a conscious effort to be socially responsible in their actions toward the society and the community. However, the approach followed is a form of invisible CSR that is part of the culture of the organization. The hospital never believed in marketing their CSR efforts for building the brand image of the hospital.

There is a 'green card' initiative provided to the public who are below poverty line (BPL) by the government. All the green card holders are provided medical services as per government specified limits.

Manipal Arogya card (MAC): The Manipal Arogya card is issued by the Manipal University, as part of CSR. A family consisting of four people can be enrolled for ₹ 450 per annum.

The benefits for outpatients include concessions on consultation charges, discount on diagnostic services, up to $10 \%$ discount on medicines. The benefits for inpatients are discount on hospitalization charges, for stay in special and deluxe wards (excluding consumables), up to $10 \%$ discount on medicines, coverage of accident and emergency from the date of enrolment. Arogya card enrollments take place in the month of April, May and June every year. The scheme is valid from 1st August to 31st July of the next year. A comparative analysis is carried out in Graph 1, year-on-year, to understand the trend in new and renewed applications. As both have tripled in number, year over year, it shows customers are buoyed over the corporate social initiative 
and the services provided by the card and users have showed enhanced loyalty.

Branding of the $\mathrm{KH}$ depends on a large extent to the marketing efforts of the marketing department which came into prominence from 2005.

The marketing department in $\mathrm{KH}$ utilizes various marketing strategies in order to help to build the brand of the hospital as part of the integrated marketing communications. The following observations were found:

1. Advertising and print media: The advertising media is used for the projecting about $\mathrm{KH}$ and the various services it offers in local area, e.g.

\begin{tabular}{|c|c|c|}
\hline Marketing machinery & Frequency & Example \\
\hline Pamphlets & $\begin{array}{l}\text { New service } \\
\text { offering }\end{array}$ & $\begin{array}{l}\text { Manipal Arogya } \\
\text { card }\end{array}$ \\
\hline Invites & Conferences & $\begin{array}{l}\text { Continual medical } \\
\text { education (CME) }\end{array}$ \\
\hline Television (local TV) & Modified services & $\begin{array}{l}\text { Introduction of } 64 \\
\text { slice CT scan }\end{array}$ \\
\hline Newspaper & $\begin{array}{l}\text { New service } \\
\text { offering }\end{array}$ & $\begin{array}{l}\text { Manipal Arogya } \\
\text { card }\end{array}$ \\
\hline
\end{tabular}

- The print media is also involved in publishing newspaper articles for wide geographical area coverage.

- The newspaper articles are printed in local languages such as Kannada.

2. Promotion of services: Every hospital looks to promote their services in a variety of ways. On discussions with the marketing department, it was understood that the hospital engages in promoting their services by using the help of various other media. The Vajpayee Arogya Shree (VAS) is promoted by $\mathrm{KH}$. This program offers free services to BPL card holders. The statistics of the VAS program are discussed in the later part. The corporate empanelment helps in gaining recognition and indirect publicity.

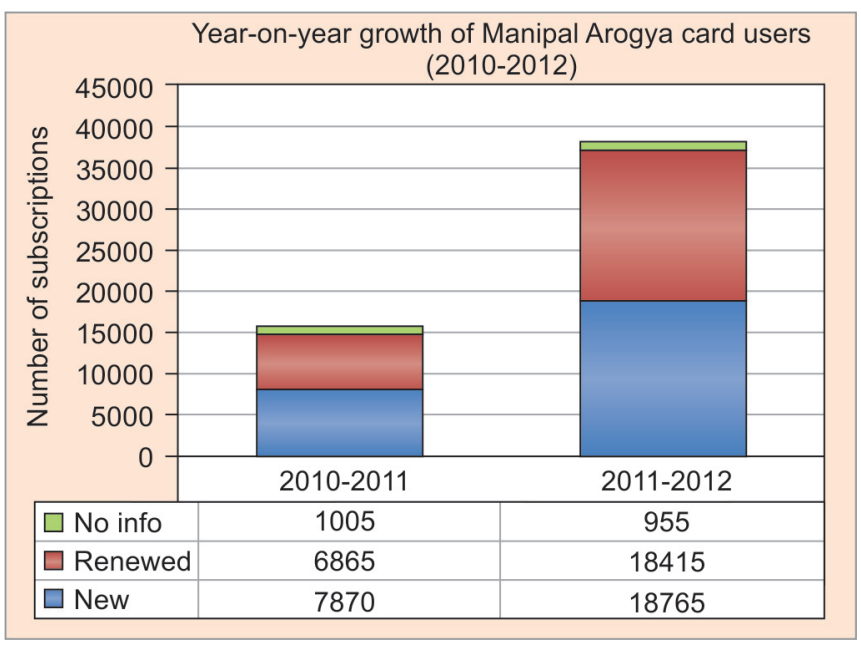

Graph 1: Utilization of Arogya card by new and renewed customers
3. Events: There are number of health events organized. The hospital follows a health calendar and celebrates special and important days in the year. Some examples of events organized are: The walkathon, Diabetes day. These events are organized to publicize the various services offered. It facilitates word-of-mouth communication which enables the community to take notice of the hospitals and the services offered by the hospital. These events are advertised by use of hoardings, pamphlet distribution and banners.

4. Public relations: The hospital maintains public relations through press coverage while organizing camps and by offering health checks to corporate houses under the Manipal Hospital's brand name.

5. Interactive marketing: Announcements are carried out about camps being conducted in a particular geographical area. The announcements are carried out in the local languages (Kannada, tulu or bohri) whichever is prevalent there.

6. Direct marketing (continual medical education programs, $C M E$ ): The hospital conducts conferences almost once every month, where doctors from the hospital interact with doctors in the surrounding areas which lack the facilities of a tertiary care hospital. There is exchange of information and direct marketing of services provided. These doctors then refer serious and chronic cases while the follow-up cases are attended to by the doctors. This forms a symbiotic relationship between the hospital and the doctors.

Another example of direct marketing is the camps that are conducted in various areas and regions. These camps can be divided into government schemed camps and special outreach camps. The information on the camps is given as follows:

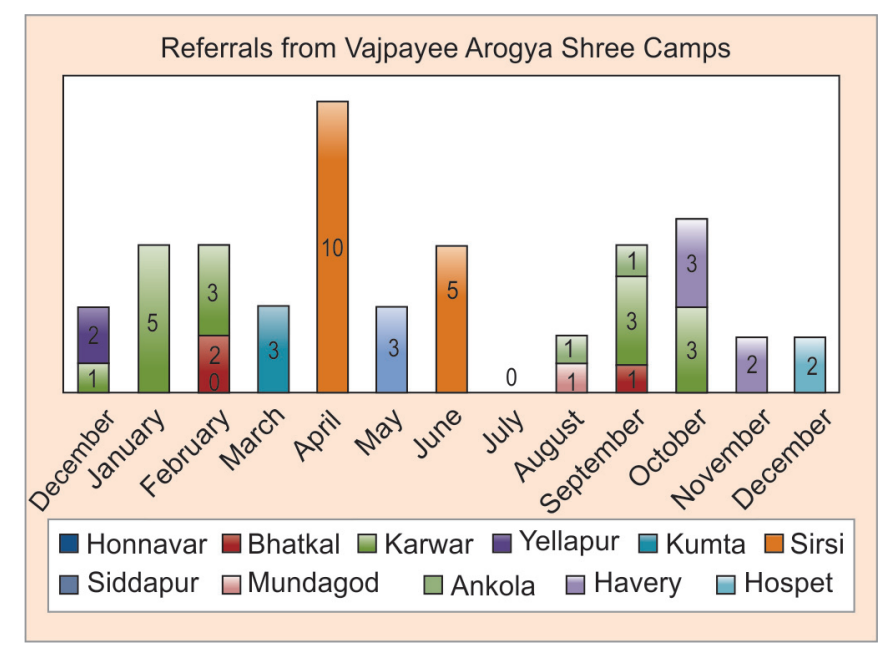

Graph 2: Referrals to tertiary hospital from VAS camps 


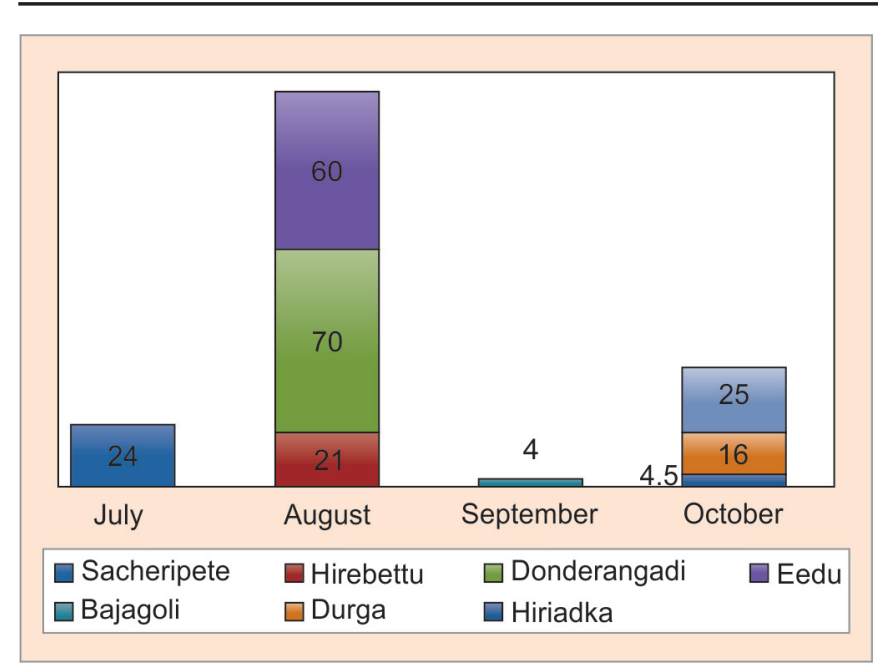

Graph 3: Referrals to tertiary hospital from NGO camps

a. Government scheme camps: These camps include the Vajpayee Arogya Shree scheme users (VAS). The camp is conducted on fixed dates twice every month by the Karnataka Government. These camps are funded completely by the Government and informed to marketing department (KH, Manipal).

The marketing department conducts a press meet at the area designated for the camps 10 days prior to the commencement of the camps which is published in the newspapers while an announcement is carried out 2 to 3 days prior to the camp. This camp mainly concentrates on the below poverty line customers who are offered free treatment at KH, Manipal. Kasturba Hospital, is later reimbursed by the VAS. Graph 2 shows the statistics of VAS camps, and it also indicates the patient traffic from different geographical areas, which helps in marketing decision making.
Graph 3 which indicates the patient traffic from particular geographical areas after conducting VAS camps.

b. Special outreach camps: The other camp wherein the marketing department plays a role is the special outreach camps which are conducted by NGOs (Nongovernment Organizations). A request through the NGO is sent to the medical superintendent. In these camps, the hospital only provides clinicians, staffs and consumables as requested by the NGOs. Graph 3 shows the statistics of the NGO camps.

\section{DISCUSSION}

The following observations were made about how the elements present in the organization helps to play an important role in building the brand image of the hospital. On direct observations, the service, culture and reputation form the basis of KH, Manipal.

Graph 4 shows the trends of patient arrivals to the hospital year-on-year between 1990 and 2012. There is a steep surge in the numbers of outpatient attendance from 2005 onwards. Amongst the new and returned customers, the customer satisfaction indices were studied for 1 year period during 2011. The customer satisfaction index is calculated with the help of feedback process undertaken by the hospital. Feedback forms $\rightarrow$ distributed to the wards and outpatient department OPD (Inpatient and outpatient) $\rightarrow$ filled and returned by the patients during discharge $\rightarrow$ data collected is updated into the software $\rightarrow$ questions and their responses are numbered as 1 to $5 \rightarrow$ one point given to each $\rightarrow$ responses are updated everyday $\rightarrow$ the CSI score is calculated every month. The average of answers to each

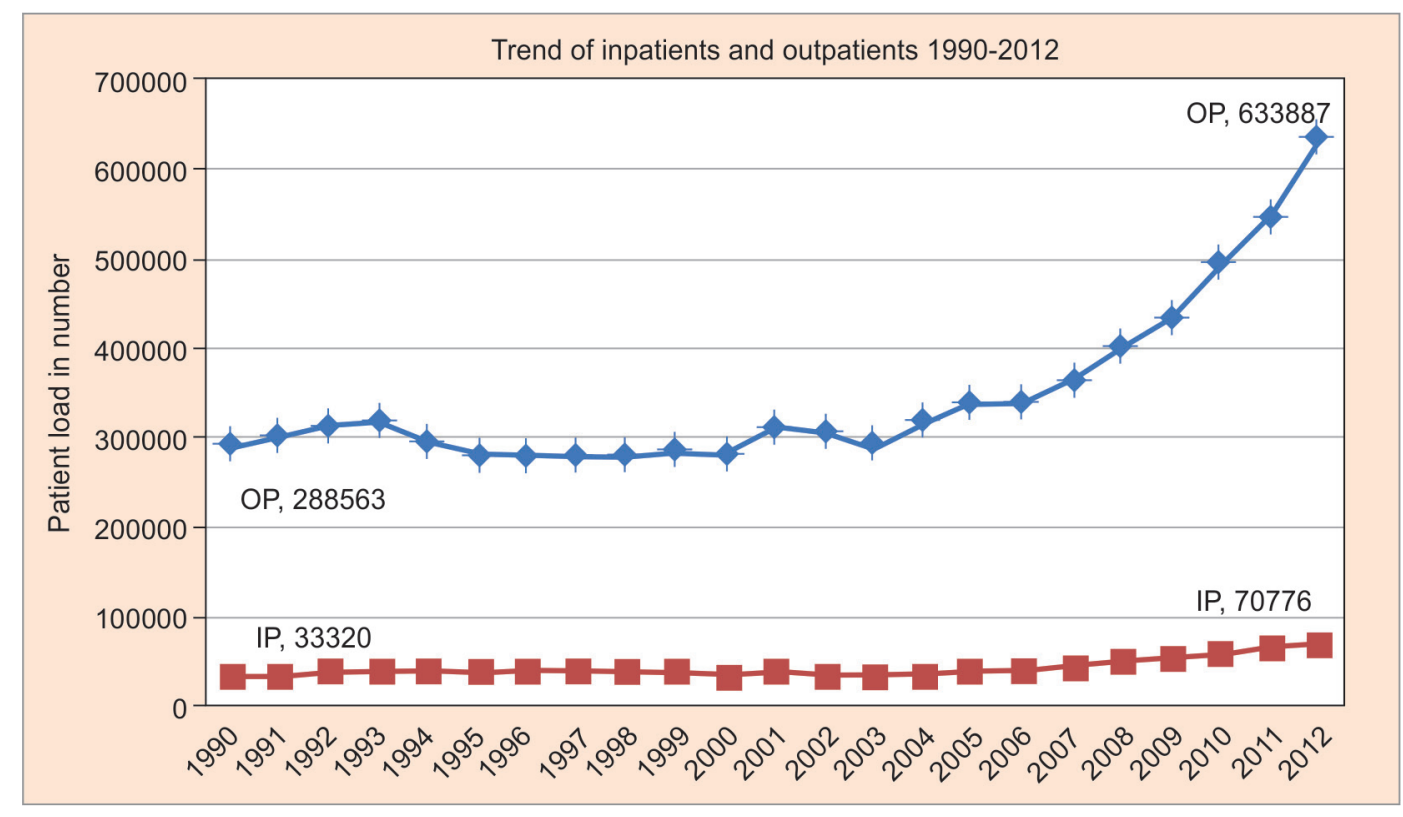

Graph 4: Trend analysis of census of hospital 


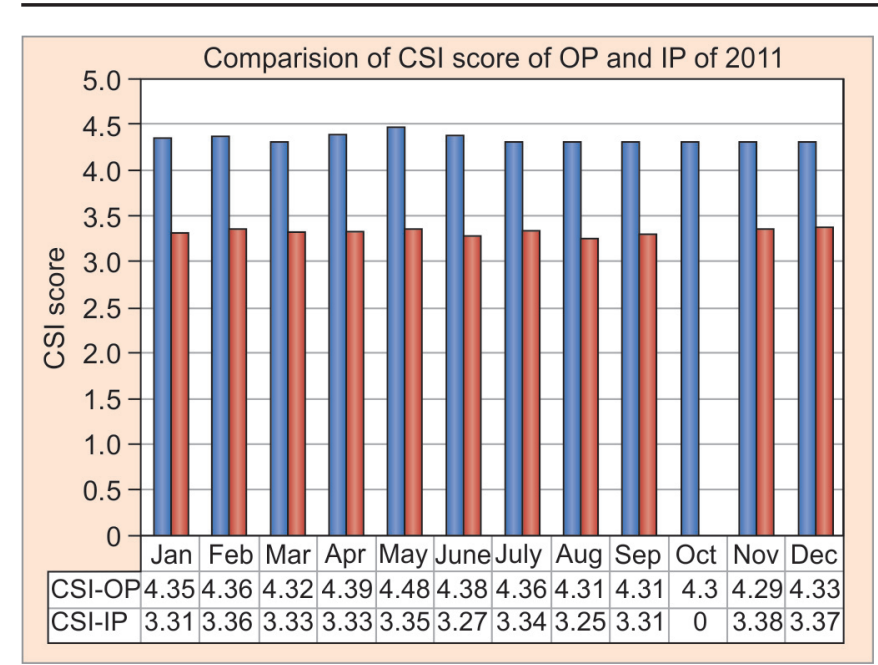

Graph 5: Customer satisfaction index (CSI) of hospital services from both outpatients and inpatients for the year 2011

question sums to 5 . So, the CSI score near to 5 is the best. The lesser the score away from 5 is seen as poor services.

The CSI score is collected for both inpatient (IP) and outpatient (OP) from the customer feedback cell for the period between January and December 2011. In 2011, the OPD census per annum were 5,50,506 and IP census per annum was 70,776 . On any day, the sample size is $10 \%$ of day's census. The questions included in the questionnaire are about courtesy of staff at reception, communications by doctors in OPD consultation chambers, waiting times at laboratory services, food in in-patient services, etc.

Likert-type scales of five points were used to the latent constructs considered in this study $(1=$ poor and $5=$ excellent).

Graph 5 shows the customer satisfaction index in the hospital for a period of 2011. The scores being above 4 consistently in every month, it is an excellent indicator from the users of the service about their satisfaction levels between very good and excellent. Most of the customers are happy with doctor's services, staff services, laboratory services. This improved customer satisfaction which will help in improving the loyalty by customers, improves brand image of the hospital, and enhance the willingness of customers to pay for the services. Customer satisfaction enhances the brand equity.

\section{CONCLUSION}

Reputation of an organization or service is extremely dynamic in nature, never constant. It is ever changing according to nature of the external forces.
One way of maintaining good reputation is with ideal marketing of services. There are various strategies to highlight services of a hospital. One of the important is the role of the print and advertising media, which has been highlighted in the study. A healthcare organization being a service organization attracts capable employees if they are provided optimum oppurtunities to enhance their knowledge. The role of camps in improving the number of patients being referred to a tertiary care center has been observed above. The role of word of mouth communication is difficult to measure, due to logistics involved.

Drawing on Mintzberg's work, different theorists stress that managers should adopt a broad perspective that integrates not only customers but also other stakeholders' interests and values to define a successful firm strategy. ${ }^{9}$ Mintzberg also suggests that stakeholders with more power should receive greater care. ${ }^{10}$ For healthcare organizations, the rewards of branding can be humongous, as it provides an opportunity to truly assess the needs of their users, develop capabilities to meet those needs and more effectively communicate the ability to meet those needs.

\section{REFERENCES}

1. Kotler P, Shalowitz J, Stevens RJ. Strategic marketing for healthcare organizations: building a customer driven healthcare system. Wiley and Sons. 2008.

2. Kim KH, Kim KS, Kim DY, Kim JH, Kang SH. Brand equity in hospital marketing. J Busin Res 2008;61(1):75-82.

3. Lee WI, Chen CW, Chen TH, Chen CY. The relationship between consumer orientation, service value, medical care service quality and patient satisfaction: The case of a medical center in Southern Taiwan. Afr J Bus Management 2010;4(4):448-458.

4. Blomqvist KH, Posner S. Three strategies for integrating CSR with brand marketing. Market Leader, October 2004;33-36.

5. Kim YK, Cho CH, Ahn SK, Goh IH, Kim HJ. A study on medical services quality and its influence upon value of care and patient satisfaction - focusing upon outpatients in a large-sized hospital. Total Qual, Management Business Excel 2008;19(11): 1155-1171.

6. Ailawadi KL, Lehmann DR, Neslin SA. Revenue premium as an outcome measure of brand equity. J Mark 2003 Oct;67:1-17.

7. Keller KL, Lehmann DR. Brands and branding: research findings and future priorities. Market Science 2006;25(6):740-759.

8. Hogan JE, Lemon KN, Rust RT. Customer equity management. Chartering new directions for future marketing. J Serv Res 2002 Aug;1:4-12.

9. Greenley GE, Hooley GJ, Rudd JM. Market orientation in a multiple stakeholder orientation context: implications for marketing capabilities and assets. J Bus Res 2005;58:1483-1494.

10. Mintzberg H. Power in and around organizations. Englewood Cliffs: NJ: Prentice-Hall. 1983. 